\title{
E-cigarette Purchase Intention through Facebook Social Media: A Cross-Sectional Study
}

\author{
Nusrat Parvin 1; Sayaka Zaman 2; Samia Amin ${ }^{3, *}$ \\ ${ }^{1}$ International Centre for Diarrhoeal Disease Research, Bangladesh. \\ ${ }^{2}$ Department of Business Studies, State University of Bangladesh. \\ ${ }^{3}$ Faculty of Medicine, Health and Human Sciences, Macquarie University, Australia. \\ *Correspondence: drsamia27@gmail.com
}

How to cite this paper: Parvin, N., Zaman, S., \& Amin, S. (2021). E-cigarette Purchase Intention through Facebook Social Media: A Cross-Sectional Study. Universal Journal of Business and Management, 1(2), 62-68. Retrieved from

https://www.scipublica-

tions.com/journal/in-

dex.php/ujbm/article/view/91

Received: July 15, 2021

Accepted: August 20, 2021

Published: August 21, 2021

Copyright: (๑) 2021 by the authors. Submitted for possible open access publication under the terms and conditions of the Creative Commons Attribution (CC BY) license (http://creativecommons.org/licenses /by/4.0/).

\begin{abstract}
Online shopping is a growing phenomenon and social media namely Facebook has radically changed consumers online purchase behaviour; especially the interactive information system of consumers, peers, and vendors. Similar to other online purchasing products or services, e-cigarette marketing in Facebook has potential. This study aims to determine the association between individual's online interaction and e-cigarette purchase intention from Facebook vape groups. A cross-sectional study was conducted among 214 respondents using the Facebook platform from September to December 2019. Data were collected via a self-administered questionnaire. The Chisquare test was used for data analyses using SPSS (version 25.0). Most of the participants were male; the mean age of the respondents was $27.41 \pm 2.1$. Total $93.9 \%$ (201 of 214) and $56.1 \%$ (120 of 214) respondents were vaper and smoker respectively. Among the non-smokers, most of the respondents were vaper ( 84 of $94,89.4 \%)$. Consumers smoking and vaping status were associated with each other $(\chi 2=6.11, P=0.01)$. There was an association between vaping status and purchase intention of ecigarettes from the Facebook vape group $(\chi 2=5.06, \mathrm{P}=0.02)$. Online interactions, namely like $(\chi 2=$ $5.88, \mathrm{P}<0.01)$, post $(\chi 2=7.16, \mathrm{P}<0.01)$ and sharing $(\chi 2=10.14, \mathrm{P}<0.01)$ of the e-cigarette related information or advertisements in social media were associated with purchase intention of e-cigarettes from Facebook vape group. This study revealed individuals vaping and online interactions were associated with an online purchase the intention of e-cigarette in Facebook. Public health researchers and policymakers might contemplate the regulatory environment of online marketing of e-cigarettes to curtail the uptake of e-cigarettes among non-smokers.
\end{abstract}

Keywords: Smoking, E-cigarette, Online interaction, Purchase intention, Facebook

\section{Introduction}

Vaping (use of e-cigarette) vaporizes e-liquid (with or without nicotine) to mimic conventional smoking [1]. It can assist with quit smoking for adult smokers [2], however, there are mixed opinions that it may be a gateway to cigarette smoking among non-smokers [3]. Some studies also shown evidence of simultaneous use of traditional cigarette and e-cigarette $[4,5]$. Additionally, studies increasingly show that e-cigarettes emit harmful substances and may expose users to chemicals and toxins such as formaldehyde or heavy metals which have potential adverse health effects [6,7].

At present, there is no clear international consensus on the appropriate regulation of the use of electronic cigarettes (e-cigarettes), with jurisdictions adopting a range of regulatory responses to this product [8-10]. Furthermore, the sales and marketing of e-cigarettes (both offline and online) has been targeting young people with their trendy features and pull them towards addiction to nicotine [11]. Even, a recent review mentioned that 
individuals may uptake or intend to vape by observation of vaping by peers, friends, family members or celebrities on social media [12]. Apart from imitation of peers vaping features, there is lack of evidence about influence to purchase e-cigarettes by peers' recommendations in social media.

Undeniably, social media, primarily Facebook, has attracted a considerable amount of attention in recent years in social network marketing which has impacted marketing communication considerably [13]. Under this innovative marketing approach, brands and consumers are connected without any limitation in time, location and means of communication as the approach facilitates a two-way communication instead of the traditional one-way communication. Evidence suggests that peer interactions in social media influences consumer's online purchase intention behaviour [13].

Online purchase intention occurs when an individual plan to buy a particular product or service in the future through any website or social networking channels via internet [14-16]. According to the Theory of Reasoned Action, consumer behavior could be predicted from its corresponding intentions [17]. Evidence shows that online interactions influence consumers purchase intention [18]. Therefore, it is very crucial to understand the consumer's online purchase intention of e-cigarettes from social media channels. Moreover, evidence suggest that e-cigarette users accessed e-cigarette information and advertising on social media platforms [19]; but there is lack of evidence about the impact of online interaction among peers to purchase e-cigarettes in social media. Thus, the current study aims to determine the association between individual's tobacco consumption status and online interaction in social media with e-cigarette purchase intention from Facebook vape groups.

\section{Materials and Methods}

The present study used a cross-sectional survey to assess e-cigarette purchase intention from social networking vape groups in Facebook. Recruitment of the participants were done from various Facebook vape groups [20]; we performed convenient and snowball sampling strategy to recruit minimum 200 participants. The participants must be age of 18 years and member of any Facebook vape groups were included.

The survey was sent to the members of several Facebook vape groups via a link invitation requesting participation. Participants who voluntarily agreed to participate in the study, could fill the online survey via Google form. By submission of this form, informed consent for this study was achieved from the participants digitally. Data was collected from September 2019 to December 2019. Ethical guidelines of Declaration of Helsinki IV were followed, and permission of conduction of this research obtained from the appropriate authority of a university board. Survey data was stored on a password-protected computer.

Data was collected using a self-administered questionnaire which was developed by an extensive review of literature and discussed among the research team to ensure relevance of each item and content validity. Prior to data collection, the survey was pilot tested in a sample with similar characteristics (excluded from the main analysis) to determine the usability of the online response system, language clarity and timing of questions.

There is total of 15 items in the questionnaire consisting of sociodemographic characteristic (country of origin, age and gender), tobacco consumption status (smoking, vaping and quit intention), online interaction in social media (social media activity such as like, share and/or post e-cigarette related information or advertisements in Facebook vape group), subjective norm, perceived enjoyment, economic benefit, trust and risk towards online purchase intention of e-cigarettes from Facebook vape groups.

Regarding the individuals tobacco consumption status, the sample was stratified for the following comparisons: (1) respondents who had never smoked cigarettes (nonsmoker) compared with those who had smoked cigarettes (smoker); (2) respondents who had never used e-cigarettes (non-vaper) compared with those who had used e-cigarettes 
(vaper); and (3) respondents who didn't want to quit smoking or vaping (non-quitter) compared with those who wanted to quit smoking or vaping (quitter).

Data was analysed using IBM Statistical Package for Social Science (SPSS) version 25.0 comprising descriptive and bivariate analysis. Descriptive statistics was used to describe characteristics of the respondents. Bivariate analysis of Chi-Square $\left(\chi^{2}\right)$ was used to measure associations between two categorical variables and recorded as frequency (n) and percentages (\%). The $\mathrm{p}$ value of $<0.05$ was considered statistically significant. We have followed STROBE (STrengthening the Reporting of OBservational studies in Epidemiology) guideline for reporting [21].

\section{Results}

This A total of 267 participates were responded to the survey questionnaire. After exclusion of missing data, only 214 competed (response rate $80 \%$ ) the full questionnaire which were included in the main analysis. There were 14 different nationalities responded in the survey, but majority of the participants were from Bangladesh (198 of 214, 92\%). Most of the participants were male (209 of 214, 97.7\%); and age below 30 years (168 of 209, $78.5 \%$ ). The mean age of the respondents was $27.41 \pm 2.1$ and ranged from 21 to 49 years old.

Regarding consumer's subjective norm, total 30.4\% (65 of 214) agreed about friends' endorsement of buying e-cigarette from Facebook vape group seller. When compared with disagreement, only $25.3 \%$ (54 of 214), 32.3\% (69 of 214), $25.7 \%$ (55 of 214) and $23.4 \%$ (50 of 214) of the participants agreed on perceived enjoyment, economic benefit, trust, and risk measures respectively. Distribution of consumer's responses regarding these measures had been reported in Table 1 .

Table 1. Distribution of participants responses $(\mathrm{N}=214)$

\begin{tabular}{|c|c|c|c|}
\hline & $\begin{array}{l}\text { Disagree } \\
\text { N (\%) }\end{array}$ & $\begin{array}{l}\text { Neutral } \\
\text { N (\%) }\end{array}$ & $\begin{array}{l}\text { Agree } \\
\text { N (\%) }\end{array}$ \\
\hline $\begin{array}{l}\text { Consumer's Subjective Norm } \\
\text { Most of my friends think that buying e-cigarette } \\
\text { through the Facebook seller is a good idea. }\end{array}$ & $92(43.0)$ & $57(26.6)$ & $65(30.4)$ \\
\hline $\begin{array}{l}\text { Consumer's Perceived Enjoyment } \\
\text { I will enjoy vaping if I buy form this face group page }\end{array}$ & $76(35.5)$ & $84(39.2)$ & $54(25.3)$ \\
\hline $\begin{array}{l}\text { Consumer's Perceived Economical Benefit } \\
\text { Purchased e-cigarette from this Facebook group will } \\
\text { save some money }\end{array}$ & $74(34.5)$ & $71(33.2)$ & $69(32.3)$ \\
\hline $\begin{array}{l}\text { Consumer's Perceived Trust } \\
\text { E-cigarette purchased by using Facebook will be trust- } \\
\text { worthy }\end{array}$ & 74(34.5) & 85 (39.8) & $55(25.7)$ \\
\hline $\begin{array}{l}\text { Consumer's Perceived Risk } \\
\text { Online purchased e-cigarette is not as good as expected }\end{array}$ & $76(35$ & $88(41.1)$ & $50(23.4)$ \\
\hline
\end{tabular}

Regarding the tobacco consumption status of the individuals, majority of the respondents were smoker (120 of 214, 56.1\%), vaper (201 of 214, 93.9\%) and willing to quit either smoking or vaping (180 of $214,84.1 \%)$. Among the non-smokers, majority of the respondents were vaper ( 84 of $94,89.4 \%$ ). Total $97.5 \%$ (117 of 120 ) respondents were both smoking and vaping concomitantly. Moreover, majority of the respondents mentioned affirmative responses for like (140 of $214,65.4 \%)$, post (115 of $214,53.7 \%$ ) and share (153 of $214,71.5 \%$ ) e-cigarette related information or advertisement in the Facebook vape 
groups. Overall, total 53.3\% (114 of 214) respondents' intent to purchase e-cigarette from Facebook vape groups.

Consumers smoking and vaping status were associated with each other, which was revealed by Chi square $(\chi 2=6.11, \mathrm{P}=0.01)$. Additionally, based on Chi square analysis (Table 2), there was an association between vaping status and consumers purchase intention of e-cigarettes from Facebook vape group $(\chi 2=5.06, P=0.02)$. But smoking $(\chi 2=0.72$, $\mathrm{P}=0.39)$ and quitting $(\chi 2=2.37, \mathrm{P}=0.12)$ status were not associated with consumers purchase intention of e-cigarettes from Facebook vape groups (Table 2).

Table 2. Association between tobacco consumption status and online purchase intention $(\mathrm{N}=214)$

\begin{tabular}{|c|c|c|c|c|c|}
\hline & & \multicolumn{2}{|c|}{ Purchase Intention } & \multirow[t]{3}{*}{$x^{2}$} & \multirow[t]{3}{*}{ p-value } \\
\hline & & Yes & No & & \\
\hline & & $\mathbf{N}(\%)$ & $\mathbf{N}(\%)$ & & \\
\hline \multirow{2}{*}{$\begin{array}{c}\text { Smoking } \\
\text { status }\end{array}$} & Smoker & $67(55.8)$ & $53(44.2)$ & 0.72 & 0.39 \\
\hline & Non-smoker & $47(50.1)$ & $47(50.1)$ & & \\
\hline \multirow{2}{*}{$\begin{array}{l}\text { Vaping } \\
\text { status }\end{array}$} & Vaper & $111(55.2)$ & $90(44.8)$ & 5.06 & $0.02^{*}$ \\
\hline & Non vaper & $3(23.1)$ & $10(76.9)$ & & \\
\hline \multirow{2}{*}{$\begin{array}{l}\text { Quit sta- } \\
\text { tus }\end{array}$} & Quitter & $100(55.6)$ & $80(44.4)$ & 2.37 & 0.12 \\
\hline & Non quitter & $14(41.2)$ & $20(58.8)$ & & \\
\hline
\end{tabular}

*Significant at level $\mathrm{p}<0.05$

Chi square test also revealed that online interaction namely like $(\chi 2=5.88, P<0.01)$, post $(\chi 2=7.16, \mathrm{P}<0.01)$ and sharing $(\chi 2=10.14, \mathrm{P}<0.01)$ of the e-cigarette related information or advertisements in social media were associated with consumers purchase intention of e-cigarettes from Facebook vape groups (Table 3).

Table 3. Association between online interaction in social media and purchase intention $(\mathrm{N}=214)$

\begin{tabular}{|c|c|c|c|c|c|}
\hline & & \multicolumn{2}{|c|}{ Purchase Intention } & \multirow[t]{2}{*}{$x^{2}$} & \multirow[t]{2}{*}{ p-value } \\
\hline & & Yes N (\%) & No N (\%) & & \\
\hline \multirow[t]{2}{*}{ Like } & Yes & $83(59.3)$ & $57(40.7)$ & 5.88 & $<0.01^{*}$ \\
\hline & No & $31(41.9)$ & $43(58.1)$ & & \\
\hline \multirow[t]{2}{*}{ Post } & Yes & $71(61.7)$ & $44(38.3)$ & 7.16 & $<0.00^{*}$ \\
\hline & No & $43(43.4)$ & $56(56.6)$ & & \\
\hline \multirow[t]{2}{*}{ Share } & Yes & $92(60.1)$ & $61(39.9)$ & 10.14 & $<0.00^{*}$ \\
\hline & No & $22(36.1)$ & $39(63.9)$ & & \\
\hline
\end{tabular}

*Significant at level $\mathrm{p}<0.05$

\section{Discussion}

Authors This study revealed that majority of the respondents were smokers and vapers. Among the non-smokers, majority of them were vaper which is an alarming issue. The results also showed that individuals vaping status and online interactions were associated with e-cigarette purchase intention from Facebook vape groups. Individuals smoking and quitting status were not associated with consumers purchase intention of e-cigarettes may implied the debate on use of e-cigarettes as a quit smoking tool. Overall, half of the total respondents were intended to purchase e-cigarette from Facebook vape groups. The findings of this research indicate that the extant literature may not adequately explain factors that either discourage or encourage consumers when buying e-cigarettes online in the social media context where this study might add a definite merit. 
Though e-cigarettes were deigned to support quit smoking [2], but prior studies suggested the uptake of e-cigarettes among non-smokers [3] or dual use of vaping and smoking $[4,5]$ which aligned with the findings of our current study. Even a recent study also mentioned that even never e-cigarette users searched information about e-cigarettes in the social media [19]. Our study also revealed the association between vaping status and consumers purchase intention of e-cigarettes from Facebook vape group; but individuals' smoking or quitting status were not associated. Thus, to avert smoking and endorse ecigarette as a quit smoking aid, the policymakers might apprehend the marketing strategies of e-cigarettes in social media.

In our study, when compared with disagreement, overall, one third of the sample population agreed friends' endorsement, perceived enjoyment, economic benefit, trust and risk measures of purchase intention of e-cigarettes from Facebook vape group seller. These factors were also considered for online purchase of other products like clothing materials [22]; food and beverage [23]; wine [17], from various social media sites $[16,18,24,25]$ namely Facebook [26] and Instagram $[27,28]$. Furthermore, half of the respondents of our study intended to purchase e-cigarette from Facebook vape group which congruent with previous evidence of consumers online purchase intention in various social media platforms $[26,28]$.

Social media become an integral part of our lifestyle; it creates the opportunities for sharing information via online communications; especially social interaction is the key instigator. Evidence suggested that social interactions via comment, like or sharing of the social media posts by a peer affects purchase intentions of the consumers [29,30]. Our study finding had similar result, online interaction about e-cigarette related information or advertisements in social media were associated with consumers purchase intention of e-cigarettes from Facebook vape groups. Evidence also suggested that peer communications provoked purchasing decisions which might lead to the astonishing growth of ecommerce [24]. Like other technologies, social media can facilitate social change and changes in vaping practices; therefore, further research may be useful to understand whether online marketing of e-cigarettes target non-smokers or non-vapers.

This study involved getting information about consumers purchase intention of ecigarettes from social media platform. The target respondents were familiar with the Facebook and use this social media in their routine life. Although data from an online survey may not be as precise as behavioural observation, but the key strengths of an online selfadministered survey are mainly cost, accuracy and convenience. Therefore, the major strength of this study was the data collections method via online self-administered questionnaire from Facebook vape groups.

This study also attempted to expand the understanding of factors influencing purchase intention of e-cigarettes from social media platform. Although the endeavour was worthwhile, it was not without its limitations. There was the possible problem of selfreporting and multi-responses in this study, it is possible that results were biased toward customers who were willing to join this survey. The data obtained could raise the question of external validity. This limitation did not minimize the significance of the results or findings in this study. The above point was mentioned to direct the attention of future research identifying and aiding further improvement in this area.

In today's technologically advanced era, the intention to buy online is affected by both technology factors and socio-cultural factors. This study explored both factors namely the online interaction culture and individual's tobacco consumption influence on e-cigarette purchase intention from social media. Findings of this research will provide insight to the public health research and e-commerce managers about the consumers online purchase intentions of e-cigarettes in social media context. Additionally, the policy makers might induce regulatory strategies of the online marketing of e-cigarettes to mitigate the uptake of e-cigarettes among the non-smokers which is the most crucial concern. 
As the available bandwidth for communication increases, it is expected to lead to a greater use of the technology in the everyday lives. Future studies should incorporate additional technology factors as well as income, education, content of the e-cigarettes specially e-liquid containing nicotine. A longitudinal study could be designed to understand consumers behaviour regarding purchase intention of e-cigarettes in social media which may change over time.

\section{Conclusions}

This study found that consumers tend to purchase e-cigarettes from Facebook vape groups due to online interactions. Public health researchers, policy makers and e-Marketing managers must find the right formula with the right marketing mix concerning use of e-cigarettes for quit smoking tool, not as a trendy product among the non-smokers which might be high protentional to be addicted if contain nicotine.

Author Contributions: Conceptualization, methodology, writing-review and editing, N.P. and S.Z.; Conceptualization, writing - original draft preparation, supervision, S.A. All authors have read and agreed to the published version of the manuscript.

Funding: This research received no funding.

Data Availability Statement: Data is not publicly available, only available by requesting email to corresponding author.

Acknowledgments: Participants for their valuable time and support.

Conflicts of Interest: The authors declare no conflict of interest.

\section{References}

[1] Grana R, Benowitz N, Glantz SA. E-cigarettes: a scientific review. Circulation. 2014; 129:1972-1986. doi: https://doi.org/10.1161/ CIRCULATIONAHA.114.007667

[2] Bullen C, Howe C, Laugesen $\mathrm{M}$ et al. Electronic cigarettes for smoking cessation: a randomised controlled trial. Lancet, 2013; 382(9905), 1629-1637. doi: https://doi.org/10.1016/S0140-6736(13)61842-5

[3] Best C, Haseen F, Currie D et al. Relationship between trying an electronic cigarette and subsequent cigarette experimentation in Scottish adolescents: a cohort study. Tobacco Control, 2017; 27(4), 373-378. doi: http://dx.doi.org/10.1136/tobaccocontrol-2017053691

[4] Mushtaq N, Williams MB, Beebe LA. Concurrent use of cigarettes and smokeless tobacco among US males and females. Journal of Environmental and Public Health, 2012; 984561. doi: https://doi.org/10.1155/2012/984561

[5] Marilena M, Pasquale C, Jennifer P et al. Dual use of electronic cigarettes and classic cigarettes: a systematic review. Addiction Research \& Theory. 2017; 26. 1-9. doi: https://doi.org/10.1080/16066359.2017.1388372

[6] Jensen RP, Wentai L, Pankow JF et al. Hidden Formaldehyde in e-cigarette aerosols. New England Journal of Medicine, 2015; 372(4), 392-394. doi: https://doi.org/10.1056/NEJMc1413069

[7] Williams M, Villarreal A, Bozhilov K et al. Metal and silicate particles including nanoparticles are present in electronic cigarette cartomizer fluid and aerosol. Plos ONE, 2013; 8(3), 1-11. doi: https://doi.org/10.1371/journal.pone.0057987

[8] Medicines and Healthcare Products Regulatory Agency (MHRA). Licensing procedure for electronic cigarettes and other nicotine containing products (NCPs) as medicines. Published 2017.

[9] US Department of Health and Human Services, US Food and Drug Administration. FDA's new regulations for e-cigarettes, cigars, and all other tobacco products. Published 2016.

[10] Douglas H, Hall W, Gartner C. E-cigarettes and the law in Australia. Australia Family Physician. 2015; 44(6):415-418.doi: https://doi.org/ 26209995.

[11] Chu KH, Colditz JB, Primack BA et al. JUUL: Spreading online and offline. The Journal of Adolescent Health, 2018; 63(5), 582-586. doi: https://doi.org/10.1016/j.jadohealth.2018.08.002

[12] Amin S, Dunn A, Laranjo L, Social influence in the uptake and use of electronic cigarettes: a systematic review, American Journal of Preventive Medicine, 2019; 58(1):129-141. doi: https://doi.org/10.1016/j.amepre.2019.08.023

[13] Ismail E, Chris E, The influence of eWOM in social media on consumers' purchase intentions: An extended approach to information adoption. Computers in Human Behavior. 2016; 61. 47-55. doi: https://doi.org/10.1016/j.chb.2016.03.003 
[14] Permatasari, A. Kuswadi E. The impact of social media on consumers' purchase intention: a study of ecommerce sites in Jakarta, Indonesia. Review of Integrative Business and Economics Research, 2018; 6(1):321-335.

[15] Sin S, NorcK, Al-Agaga A, Factors affecting Malaysian young consumers' online purchase intention in social media websites, Procedia - Social and Behavioral Sciences, 2012; 40,326-333.

[16] Pucci T, Casprini E, Nosi C et al. Does social media usage affect online purchasing intention for wine? The moderating role of subjective and objective knowledge, British Food Journal, 2019; 121(2):275-288. doi: https://doi.org/10.1108/BFJ-06-2018-0400

[17] Ajzen I, Fishbein M. 1980, Understanding attitudes and predicting social behavior, Prentice-Hall, Upper Saddle River, NJ.

[18] Yin X, Wang H, Xia Q et al. How social interaction affects purchase intention in social commerce: a cultural perspective. Sustainability, 2019; 11. doi: https://doi.org/10.3390/su11082423

[19] Amin S, Dunn A, Laranjo, L, Exposure to e-cigarette information and advertising in social media and e-cigarette use in Australia: A mixed methods study, Drug and Alcohol Dependence, 2020; 213: 108112. doi: https://doi.org/10.1016/j.drugalcdep.2020.108112

[20] Thornton L, Batterham P, Fassnacht D et al. Recruiting for health, medical or psychosocial research using Facebook: Systematic review, Internet Interventions, 2016; 4(1): 72-81. doi: https://doi.org/10.1016/j.invent.2016.02.001

[21] Von Elm E, Altman D G, Egger M et al. The Strengthening the Reporting of Observational Studies in Epidemiology (STROBE) Statement: guidelines for reporting observational studies. International Journal of Surgery, 2014; 12(12), 1495-1499. doi: https://doi.org/10.1016/j.ijsu.2014.07.013

[22] Rajapaksha L, Thilina D, The Influence of Facebook brand page on consumer purchase intention with reference to fashion retailing industry. Sri Lanka Journal of Marketing. 2019; 5. 55-101. doi: https://doi.org/10.4038/sljmuok.v5i1.27

[23] Freeman B, Kelly B, Baur L et al. Digital junk: food and beverage marketing on Facebook. American Journal of Public Health, 2014; 104(12), e56-e64. doi: https://doi.org/10.2105/AJPH.2014.302167

[24] Xia W, Chunling Y, Yujie W. Social media peer communication and impacts on purchase intentions: a consumer socialization framework, Journal of Interactive Marketing, 2012; 26(4): 198-208. doi: https://doi.org/10.1016/j.intmar.2011.11.004

[25] Atchara L, Anny M., Trust and risk in purchase intention through online social network: a focus group study of Facebook in Thailand. Journal of Economics, Business and Management. 2013; 314-318. doi: https://doi.org/10.7763/JOEBM.2013.V1.68

[26] James R, Guppy, Sarita G, Facebook: Investigating the influence on consumer purchase intention. Asian Journal of Business Research. 2014; 4. 1-15. doi: https://doi.org/10.14707/ajbr.140006

[27] Astuti B, Analysis on the effect of Instagram use on consumer purchase intensity. Review of Integrative Business and Economics Research, 2018; 7(2): 24-40. doi: https://doi.org/2304-1013/buscompress

[28] Jasmine C, Christy C, Dimple T, 2017. Consumer purchase decision in Instagram stores: the role of consumer trust. Proceedings of the 50th Hawaii International Conference on System Sciences.

[29] Doyduk H, Yolbulan E, Peer communication in social media and effect on purchase intention. Press Academia Procedia, 2017; 3 : 640-645. doi: https://doi.org/10.5195/emaj.2019.173

[30] Sakir E, Beril D, Osman O, The relationship with AD clicks and purchase intention: an empirical study of online consumer behaviour. European Journal of Economics and Business Studies. 2017; 9. 25. doi: https://doi.org/10.26417/ejes.v9i1.p25-33 